\begin{tabular}{|l|l|l||}
\hline \multicolumn{2}{|c|}{ PublisherInfo } \\
\hline \hline PublisherName & $:$ & BioMed Central \\
\hline \hline PublisherLocation & $:$ & London \\
\hline \hline PublisherImprintName & $:$ & BioMed Central \\
\hline \hline
\end{tabular}

\title{
We are the web
}

\begin{tabular}{|l|l|l||}
\hline \multicolumn{2}{|c|}{ ArticleInfo } \\
\hline \hline ArticleID & $:$ & 3795 \\
\hline \hline ArticleDOI & $:$ & $10.1186 /$ gb-spotlight-20001013-01 \\
\hline \hline ArticleCitationID & $:$ & spotlight-20001013-01 \\
\hline \hline ArticleSequenceNumber & $:$ & 232 \\
\hline \hline ArticleCategory & $:$ & Research news \\
\hline ArticleFirstPage & $:$ & 1 \\
\hline \hline ArticleLastPage & $:$ & 2 \\
\hline \hline & & RegistrationDate : 2000-10-13 \\
ArticleHistory & $:$ & OnlineDate \\
\hline \hline ArticleCopyright & $:$ & BioMed Central Ltd2000-10-13 \\
\hline \hline ArticleGrants & $:$ & \\
\hline \hline ArticleContext & $:$ & 130591111 \\
\hline \hline
\end{tabular}




\section{William Wells}

Email: wells@biotext.com

In random networks each pair of nodes (in this discussion, each pair of cellular metabolites) is connected randomly, with a certain probability $p$. The number of links per node ends up in a Poisson distribution, clustered around a particular value. But the internet, as an example of a scale-free network, does not fit this pattern. Such extremely heterogeneous but error tolerant networks are dominated by a few highly connected nodes, or hubs, with the number of links to other nodes dropping off as described by a power law. In the 5 October Nature, Jeong et al. report that cellular metabolism resembles the latter pattern of a scale-free network (Nature 2000, 407:651-654). Jeong et al. use the WIT database [http://igweb.integratedgenomics.com/IGwit/] to analyze metabolic networks from 43 organisms representing all three domains of life. Despite significant variation in individual constituents, all networks show the same scaling properties. The networks have the unique attribute of conserved diameter, meaning that the shortest biochemical pathway between any two constituents remains the same regardless of the size of the network. This is possible only because substrates present in more complex organisms participate in more reactions.

\section{References}

1. Emergence of scaling in random networks.

2. Error and attack tolerance of complex networks.

3. Nature, [http://www.nature.com/nature/]

4. What is there?, [http://igweb.integratedgenomics.com/IGwit/] 